José María Tejedor. An Introduction to English Literature with Selected Readings. Coll. Ricardo Navarrete, chs. 7 and 8. Sevilla: Kronos, 1995, XIX + 614.

As the author states in the Preface, this volume is "designed for first and second year students at Spanish Universities where a course such as an 'Introduction to English Literature' is a requirement for English majors and a common option to all sorts of students." The work suits the needs of undergraduates and university tutors for an introductory guide to the history of English literature from the Anglo-Saxon period to the present day. Its general plan is that of a very illuminating diachronic introduction, but it also furnishes a more detailed analysis of the relevant works of the different periods. It offers a comprehensive general study, yet maintains a high academic level, keeping footnotes and literary jargon to a minimum and with an up-to-date vision of the discipline.

On the other hand, this volume represents, to the best of my knowledge, the first introduction to English literature to have been published completely in English-in Spain-to meet the needs and requirements of those reading English, either as a first or second option, within the new modular system. The speed of publication alone would make it a relevant book, since it represents a contribution of Spanish lecturers to their field of English literature. Another aspect to be taken into account is that it is published by a private Spanish publishing house, whose volume of English publications will hopefully increase in the near future. However, even leaving aside these extrinsic-albeit fundamental-characteristics, the importance of the book is obvious due to its intrinsic value.

With this book we not only have a serious guide to the study of English literature but also some of the most outstanding texts from the literary production of the different periods. As an anthologizer, the author is innovative and classic at the same time. A great variety of texts is included at the end of each chapter, incorporating less known contemporary authors such as Jefferey (sic) Simons and Matthew Sharpe, together with Chaucer, Shakespeare or Dryden, for example. The selection of texts by the major authors is also balanced. We can find, in every chapter, classic excerpts together with other not so famous pieces: for instance, a "Burlesque of Lope de Vega" by Samuel Johnson, quite appropriate for Spanish readers; or "L'Allegro" and "Il Penseroso" by John Milton together with a more predictable extract: book 1 of Paradise Lost. Thus, the selected readings offer variety and provide students with an excellent, brief anthology that gives a wide perspective on the literary production of the British Isles. All these points make the book a valuable tool for teaching purposes.

One of the issues that must be taken into account when writing a book such as this is selection. That is, "important" texts, famous authors, and relevant literary movements and tendencies must be merely named or simply left out if a thorough study of others is attempted. This leads us to the controversial topic of the literary cannon and its various revisions. As José María Tejedor states, the one "included in the content units is quite narrow" and "it only mentions several major authors"; it could not be otherwise in a work of this nature. The only objection might be that this fact, along with the organization of chapters 5 and 6, entitled respectively "Eighteenth-Century Literature: 1700-1798" and "Romantic Poetry: 1798-1897" makes it impossible to include a study of some eighteenth- 
century prose writers and novelists-particularly women-who are being increasingly read now at the end of the twentieth century. Jane Austen is the clearest example of this omission, since only one paragraph is devoted to her (292), in a section entitled "Romantic Poetry" including detailed studies of other authors and works.

The organization of the book is diachronic, with eight chapters about the different ages of literature from the Old English period to the twentieth century. It is made complete by an Introduction, two Appendices, a short bibliography section and a complete Index. The Introduction offers a description of what the main characteristics of a text are for it to be considered "literature," and an analysis of the features of the different literary genres. That task might likely require several theoretical monographic studies, therefore any explicit definition is cleverly avoided by describing the general distinguishing features of the various literary forms, and through the illustration of texts belonging to different historical periods-with a clear didactic purpose. One would probably appreciate a graphical division of the different parts of this extremely helpful section, so that they could become typographically more attractive to readers.

A brief chronological table is included at the beginning of each unit so that readers may analyse the various literary developments and their impact, in the light of contemporary political, social and intellectual British and European events, particularly those Spanish. Concerning Anglo-Saxon Literature, upon defining what is understood by the term, the author analyzes briefly the prose of the period and offers a panoramic view of the religious, elegiac, and epic poetry to finish with a study of Beowulf. Complementing a detailed discussion of the different texts, useful information is provided about their location. It is also interesting to find the original text of the Hymn of the Creation by Caedmon, followed by two different versions - one rather literal, and another a more elaborate translation-in order to show the process of translating and the real flavour of Anglo-Saxon texts.

The second chapter covers medieval literature from 1066 to 1510. Its first section is devoted to Middle English poetry, wherein we find a penetrating exploration of the alliterative revival, the ballad and the romance as characteristic literary forms of the period, with a synopsis of the main features of the latter, followed by analyses of medieval prose and drama in their various manifestations. The last part of the chapter describes Chaucer's The Canterbury Tales and its qualified position in the literary panorama of his time. As stated above, the selection of readings is exceptional in that it illustrates intertextuality offering, for example, the medieval popular ballad The Ballad of Sir Gawain, "a retelling of a popular story that is also the main plot of 'The Wife's Tale' in Chaucer's The Canterbury Tales" (54).

Renaissance literature is dealt with in the light of a scholar's general introduction made by a scholar, thus including all the main points relevant to understanding this excellent literary production, but also including textual problems and their implications, as well as illuminating graphics on the physical structure of Elizabethan theatres and private banqueting-halls. These graphics and tables offer precise data from modern research in the field, as both text and notes substantiate, and they prove to be very useful to students at all levels. The same could be said of the table in chapter 5 (217) with a 
synthesis of eighteenth-century concidences and/or differences between novels and romances, to illustrate the origins of the genre.

As Ricardo Navarrete and Tejedor suggest, chapters 7 and 8 offer a slightly different structure and method. As the literary cannon is not so well established for nineteenth- and particularly twentieth-century literature, their answer is to offer a more general study without singling out literary figures, although-as the volume proves-some writers can never be overlooked in any study.

The two Appendices: "Writing a Paper" and "Terminology" represent a very complete synthesis, giving students a solid guide on how to write essays, including not only general ideas, but also pointing out general mistakes, offering even synonyms, and describing strategies on how to write for meaning. Appendix II supplies a time-saving "map" for problems big and small concerning literary terms. It proves essential when trying to check for the appropriateness of the terms we use and their exact meanings, thus serving as a veritable dictionary of dictionaries.

In view of the favourable aspects reviewed above, I feel this book will be of great interest to all those involved in literature, be they students or teachers. It contains clear insights and the issues are intelligently presented. A useful guide that will be invariably revisited.

María Jesús Lorenzo Modia

\section{Susana Onega, ed. Telling Histories: Narrativizing History, Historicizing Narrative. Amsterdam and Atlanta: Rodopi, 1995, 208 pp.}

The interest in the relation between historical texts and fictional narratives is, in many ways, typically "postmodern." The question of how historical figures, events and social attitudes can be thematized and appropriated in fiction is a subject that has enjoyed currency throughout the 1980s-now partially enhanced by the practice of the so-called "cultural studies." Supported by the works of several contemporary philosophers and critics, such as those of Jean-François Lyotard, Paul Ricoeur and Hayden White, literary studies have over the last two decades witnessed the foregrounding of the common links between history-writing and fiction-making and, consequently, the growing relevance of the principles of historiography to our understanding of the different cultural and literary traditions.

As a (foreseeable) consequence, literary critics and theorists also share this concern with the question of historical representation. Susana Onega's edited collection of essays is a good instance of this contemporary interest in what Linda Hutcheon has labeled "historiographic metafiction"- that is, the tendency of fiction to engage the question of how the discourse of history is constructed, (self-)validated and imposed on individuals by institutions (sometimes by thematizing it, sometimes in its own structure). Telling Histories, which brings together papers and lectures read at a Symposium on History and Literature held at the University of Zaragoza in early 1993, is intended to add new and refreshing considerations to the study of the interchange betwen history and literature. The 